\title{
Designing Teenage Emotions with a Life of their Own
}

\author{
Neil Winterburn, Peggy Gregory, Dan Fitton
}

\begin{abstract}
In this chapter, two participatory design activities are described in which teenagers create lo-fi designs describing emotions and explain the rationale for their design choices. Designs annotating and describing emotions are categorised as anthropomorphic, abstract, object based, or biomorphic. The chapter concludes: (i) teenagers use a variety of visual metaphors to describe emotions, (ii) teenagers use anthropomorphic visual metaphors most often to describe emotions and (iii) teenagers make more use of abstract and biomorphic visual metaphors to describe 'negative' emotions. The effect of materials on designs is analysed, suggesting that teenagers are more likely to create designs describing emotions featuring anthropomorphic visual metaphors when using malleable three-dimensional materials. Suggestions are made for the use of externalisation and personification as part of interactive emotion displays within affective systems. A focus group evaluation of a prototype mobile app is described, which suggests that teenagers place more importance on an affective systems ability to support social relationships than they do its ability to support psychological development. This research will be of value to interaction designers and Child-Computer Interaction researchers seeking to understand how teenagers use different visual metaphors to describe different emotions
\end{abstract}

\section{Introduction}

In this chapter, we describe an empirical study designed to capture teenagers' lo-fi designs describing emotions and an evaluation of a prototype mobile app. The goal of this work is to explore how teenagers represent and reason about emotion, in order to design applications allowing teenagers to externalise and personify their 
emotions. This work grew out of creative workshops with young people organised as part of earlier projects exploring approaches to visualising thoughts and feelings with digital technology. Understanding how teenagers use visual metaphors to describe different emotions is important to interaction designers, Teen-CI researchers creating technologies involving emotions, and individuals' working with teens more broadly (e.g. psychologists, teachers).

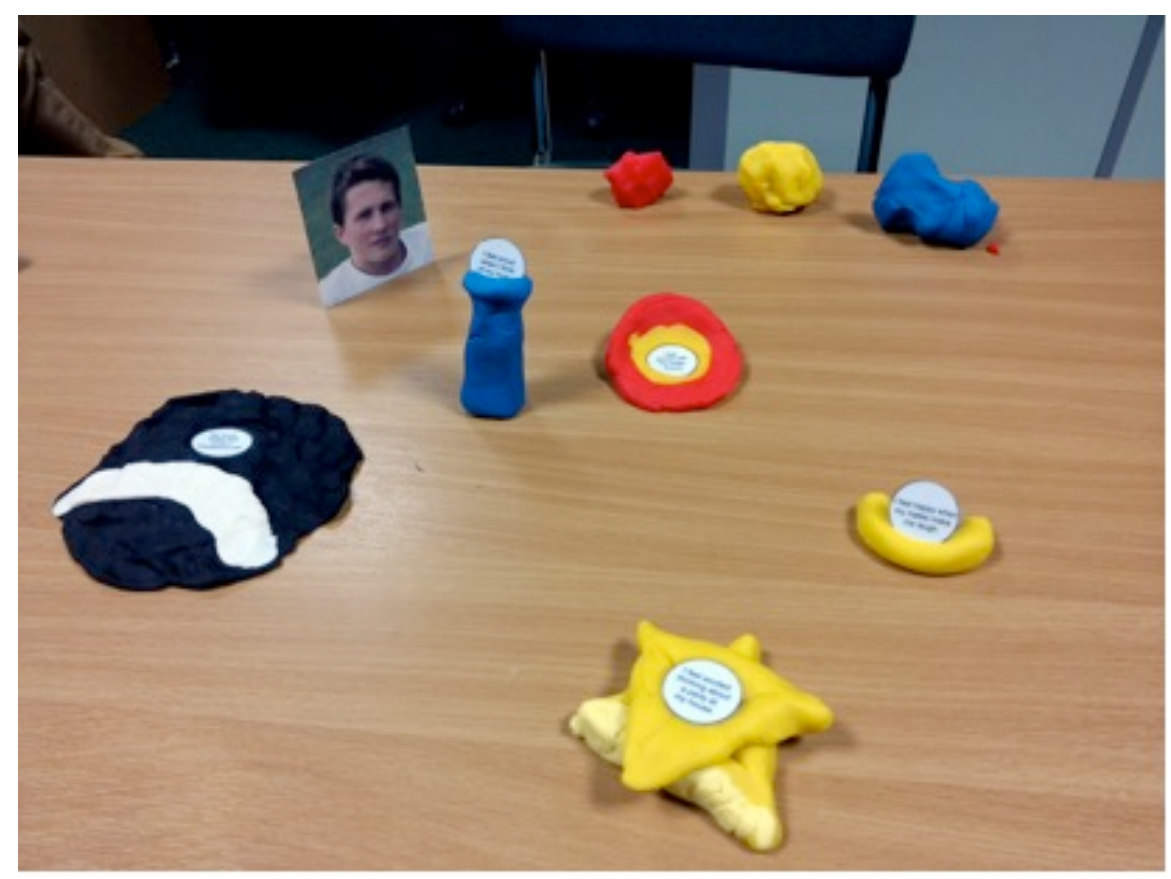

Fig 1. Play-Doh designs representing different emotions experienced by the Teen Persona 'Gary'.

The participatory design of affective systems for teenagers is a new area of research that covers many domains. It combines the multidisciplinary field of ChildComputer Interaction (CCI), which incorporates 'psychology, and especially developmental psychology, learning sciences, product and interaction design, computer science, media studies, and game design' (Read \& Markopoulos, 2013). It also incorporates the multidisciplinary field of Affective Computing, which includes computer science and in particular artificial intelligence, cognitive science, also emotion theory, art and entertainment, health and wellbeing.

Fonagy et al. (2003) have stated that the ability to describe and find meaning in emotions is of vital importance to teenage development and mental health. The popularity of mobile apps and games among teenagers provide a useful platform for designers seeking to support teenage emotional and psychological development 
outside of formal school and therapy settings. The participatory design activities described in this study were devised to give voice to teenagers in the design process and to support their emotional and psychological development.

In line with Bang et al's (1993) taxonomy of motivations for constructive design research, the motivational context for this study is a mixture of a practice based/artistically inclined approach and an empirical or technological provoked approach. The practice-based motivation for this research was to further explore observations made about the design contributions shared by teenagers participating (Bishop, 2005) in a previous art project known as Flunstellas (Froggett, 2011), which aimed to engage teenagers in producing creative visualisations of ideas, emotions and memories..

During adolescence teenagers are undergoing intense development and change, including a quest for identity. Fonagy et al (2002) state that these changes provide them with 'a far more complicated set of thoughts about his own and others' feelings and motivations.' These 'new ways of thinking and feeling about people's feelings and behaviour, as well as about his own feelings and behaviour, can be overwhelming, and the adolescent needs to absorb the implications' (Fonagy et al., 2002).

In response to these challenges faced by teenagers, the applied context for this chapter was the development of a novel mobile app. The app was intended to support teenagers in describing and interpreting complicated and mixed emotions by externalising and personifying them as virtual autonomous agents (Reynolds, 1999). Users interact with these emotions as they move around an environment, competing and interacting with one another. The mobile app has two purposes, the first is to support teenagers in better describing and understanding how they and other people experience mixed emotional states, and the second is to share these descriptions and understandings with others. Resnick's (1997) motivation to develop StarLogo was to enable children to explore decentralised systems found in the natural world by building their own simulations. Similarly the motivation for this work was to develop new empirically-grounded, conceptual and computational tools that support teenagers to explore decentralised models of cognition and affect (Velásquez, 1997). The complex and abstracted nature of decentralised models of emotion raises complex and new design challenges. Specifically, which kind of visualisation methods can be used to display emotions as autonomous agents in a way that is accessible and meaningful to teenagers? To address this design problem it is important to understand both the kinds of visual metaphors that teenagers use to describe emotions and the most effective methods for discovering them. The two studies described in this chapter were designed to explore the following research questions:

RQ1. Which kinds of visual metaphors do teenagers use to describe emotions? 
RQ2. How does the use of different materials affect teenage designs of affective displays?

\subsection{Related Work}

This section gives an overview of affective computing and the involvement of teenagers as design partners in the field of Teen-CI. It goes on to review emotion theory, the development of teenage theories of mind and techniques to externalise and personify emotions from family therapy.

\subsubsection{Affective Computing}

Affective computing is the study of computing systems that recognise, interpret and simulate human emotions. Picard (1995) defines the research of emotion in Computer Science as "computing that relates to, arises from, or influences emotions.' Highly influenced by Sentics (Clynes \& Menuhin, 1977), Picard focused particularly on the use of computers to sense, reproduce and transmit emotions. She cites a range of applications for emotionally intelligent, wearable and ambient systems to be used in education, entertainment and the workplace. Boehner et al (2007) challenged the dominant model of affective computing in which emotion is considered to be a discrete form of objective data. Instead they emphasise the socially constructed discourse within which emotion is produced. They suggest that instead of being designed only to measure and transmit our emotions, affective systems should also be designed to support the negotiation of subjective interpretations of emotion. The success of such a system would be measured by 'whether users find the system's responses useful for interpreting, reflecting on, and experiencing their emotion' (Boehner et al., 2007). As this research aims to develop tools to support teenagers describe emotions and negotiate their meaning, it operates within the Boehner's emotions as an interaction paradigm.

\subsubsection{Child Computer Interaction}

One of the dominant themes in CCI literature is research seeking to better understand children's involvement in the design of technology (Mazzone et al 2008). In their discussion about the distinction between CCI and Human Computer Interaction (HCI), Read and Bekker (2011) note the lack of control that children often have when they engage with technologies and their discretionary use of 
technologies. Furthermore, Read and Markopoulos (2013) identify research into the participation of children in the design of new technologies as an important challenge for the future. Guha et al (2004) argued that as technology is becoming an increasing part of children's lives, then children should be actively involved in its design. It has also been argued that participation also benefits designers (Guha et al 2005). In response to her frustrations with levels of control and authorship offered to children in participatory design studies, Druin (1999) pioneered the cooperative design method. By emphasizing small numbers of children having high levels of participation over long periods of time, this method places children alongside other specialists in a multidisciplinary team.

Given the practical and time-based constraints of many CCI projects and the desire to engage with large groups of children, Read et al (2006) developed the MESS (Mad Evaluation Sessions with Schoolchildren) day format. At MESS days groups of around 5 children rotate around a carousel of design and evaluation activities, participating in a wide range of activities in a short space of time. In the literature a variety of processes have been proposed for analysing children's designs of interactive systems after participatory design sessions. Xu et al (2009) describe a method for analysing the component parts of children's drawings of their experience of tangible media. Aspects of drawings were categorised according to user experience metrics and statistical analysis was then applied, to ensure that meaningful results were achieved. Read et al (2013) conducted a design study to test the effect that materials had on children's design contributions for organic interfaces. Designs were categorised as being driven either by the affordance of the materials, or by a particular design idea. The study found that materials had an effect on designs created for organic interfaces, with over half of the designs categorised as being driven by the materials. This chapter describes new techniques to analyse teenage designs of affective displays that are informed by the methods of Xu et al (2009) and Read et al (2013). Affective learning (Picard et al., 2004) sets out a framework for children's engagement with affective technologies within constructionist pedagogy (Chaptert \& Harel, 1991). The affective learning framework focuses on children's right to participate in the building of emotions sensing systems, rather than how emotions might be used, displayed and interpreted. Our chapter not only includes teens in the design process, but also stands in contrast to it because we focus on the ways in which they describe and relate to emotions using psychological techniques.

\subsubsection{Teenagers as Design Partners}

Teenagers are generally defined as young people between the ages of 13 and 19 . For the purposes of understanding teenagers as participants in Interaction Design, Fitton et al (2013) identified the following key traits including.

- Desire for independence and autonomy. 
- Desire to develop/maintain individual identity.

- Desire for association with peers.

- $\quad$ High susceptibility to peer influence.

- Willingness to take risks.

Teenagers have been identified as being of particular interest as participants in design and evaluation studies. Read et al (2013) stated that their child like tendencies coupled with their increased cognitive capacities can mean that 'In many situations, and given the right tools, teenagers may be the best evaluators of technologies, and with their imaginative risk taking minds, the best designers of products. Teen-CI researchers designing with teenagers have used a variety of different methods and techniques. Horton et al (2012) describe the use of teen personas to facilitate their work with a group of teenagers on the meaning of 'cool'. Amin et al (2005) worked with a group of teenagers to design an interface to give affective context to SMS texting. Findings suggested that teenagers would value the use of facial expressions, avatars, decorative text and location awareness to contextualise SMS texts. The COOL project (Mazzone, 2012) worked with teenagers from a Pupil Referral Unit to design a computer game that supports the development of emotional intelligence (Salovey \& Mayer, 1989). Design activities included devising a scoring system for different emotions and matching emotional terms to simplified facial expressions. The game produced made use of facial expressions to support players to learn how to recognise distinct emotional states in others. The COOL project is a good example of design research that benefits both the researchers and participants. Researchers gained new insights into how teenagers perceive and choose to describe emotions and the teenagers took part in creative activities that supported them to develop the ability to express and reason about emotions. This research builds on the methods developed for the COOL project, it also aims to gain new understanding of teen emotion whilst supporting the psychological development of participants, but differs to the COOL project due to its focus on the description and interpretation of complicated and mixed emotions.

Fitton and Bell (2014) identify Teen Computer Interaction as a new area within $\mathrm{HCI}$, distinct from CCI. They give an overview of the current state of developmental psychology and HCI research involving teenagers and address a set of key challenges for Teen Computer Interaction. The research in this chapter responds to Fitton and Bell's question of "What are the appropriate methodologies for engaging teenagers in HCI research?" by investigating which participatory design methods are appropriate to engage teenagers in the design of affective systems. The findings respond to the question "How can we gain insights into unknown teen populations?" by demonstrating that teenage design contributions can reveal new insights into their perceptions, attitudes and preferences towards subjects as personal as emotions and how emotions can be represented. 


\subsubsection{Emotion Research}

Since Picard (Picard, 1995) defined the field, affective computing has taken its theoretical grounding from emotion theory within cognitive science. Prinz (2012) gives an overview of how emotion theory has moved away from a purely cognitivist understanding of emotion, to one that also investigates non-cognitive emotion processing, socio-cognitive appraisals and diverse cultural practices. Hoffman (1986) belonged to a group of researchers who began to limit the processes that could be described as cognitive, by positioning non-cognitive and embodied modes of information processing as fundamental to our understanding emotion. Lutz's (Lutz, 1988) anthropological study of emotions as a part of everyday life on a south Pacific atoll, suggest that emotion is meaningful only within a particular social context. 'To experience a feeling as, say, anger, love, happiness, lust, or frustration, one must be grounded in a cultural context that makes anger, love, happiness, lust, or frustration meaningful' (Lutz, 1988). This study has developed a scheme to categorise teenage designs informed by theoretical debates between cognitivist, embodied and cultural understandings of emotion.

\subsubsection{Teenage Development and Emotion}

Theory of Mind (TOM) is a term used to describe our ability to understand our own thoughts and feelings and those of other people. The ability to apply TOM to describe and find meaning in emotions is of vital importance to teenage development and mental health (Fonagy et al. 2002). Modern developmental psychology suggests that our ability to access our own mental states and to infer those of others is constructed slowly over time. Astington et al (1990), describe children's initial development of a theory of mind, between the age of two and four, as a new developmental phase. By understanding themselves and others as 'things that think' children are able to make distinctions for the first time between objects in the world and mental representations of these objects. Chandler et al (1988) argue that a mature understanding of theory of mind, does not occur until adolescence. At this time the relativist implications of earlier developmental stages of theory of mind are applied to everyday social situations. Fonagy et al. 2002 state that the key task of adolescence is the development of the psychological self, as a distinct entity from the main parents or carers. Due to neurological changes taking place, many adolescents risk being overwhelmed by greater access to information about their own and other people's mental and emotional states. 'Thus we believe that one thing 
that drives - but can also derail - the achievement of separateness is freshly enhanced cognitive complexity, which means that the adolescent is faced with the task of integrating a far more complicated set of thoughts about his own and others' feelings and motivations' (Fonagy et al., 2002). Fonagy et al use the term mentalisation to describe the application of TOM. The ability to mentalise is key to teenage affect regulation, which itself is vital to the development of a sense of agency and self. 'The concept of mentalized affectivity marks a mature capacity of the regulation of affect and denotes the capacity to discover subjective meaning in one's own affective states' (Fonagy et al., 2002). Fitton and Bell (2014) argued that 'researchers have an ethical and moral responsibility to appreciate these developmental issues when working with teenage user group.' The research in this chapter seeks to develop interactive digital tools to support teenagers to engage in both mentalisation and mentalised affectivity. Participatory design activities used in this process were devised to support teenagers to use visual design and movement to describe and find personal meaning in their emotions, a key step in personal development.

\subsubsection{Externalisation and Personification}

Externalising is a narrative therapy practice, first introduced to family therapy by Michael White in the early 80's (White, 2006). Carey \& Russell ,2002), explain the ethos of externalisation as an understanding that 'the person is not the problem, the problem is the problem.' When working with teenagers, this can be combined with personification, the practice of attributing objects or animals with human characteristics: for example, literature for children often includes animals that can talk. Klein (1929) notes that personification is a common feature of young and older children's play. It is used as a mechanism to externalise psychodynamic conflict and make sense of family issues by transferring them into the behaviour of fantasy characters. Butler et al (2009) used puppetry within narrative therapy to support children to personify their problems and construct stories about problems in their lives. They concluded that the use of the puppet supported the children to objectify their problem and create a critical distance between themselves and it. The studies we discuss in this chapter, draw on these ideas and make use of lo-fi design activities to explore what teenagers' emotions may look like if they were to be visualised using digital technologies. This research aims to combine the use of externalisation and personification, with technological features known to appeal to teenagers, such as interaction, gameplay and networked collaboration, to describe and make sense of their emotions. The categorisation scheme developed in this study is drawn from externalisation and personification theories and techniques in the research cited. Responding to Fitton and Bell's (2014) question of 'What theory should be considered in work with teenagers?'. This chapter aims to explore if theories from 
family and developmental psychology are useful when designing affective displays for and with teenagers.

\section{Study One}

The first study was an exploratory participatory design activity. The EGG model (Marti \& Rizzo, 2003) is a framework that can be used by designers to categorise the context of their design activity (as reactive, proactive or emergent) in order to help decide the techniques that would be most appropriate to employ. This activity was situated in the Emergent phase of the EGG model, which is typically conducted during the brainstorming or early design phases of a project. To support innovative design thinking the activity was framed using a fantasy narrative in which emotions are externalised as things with a life of their own, visible to other people. To ground this narrative in a real world use context, two other techniques were used, a set of teen personas and a scenario featuring a classic teen dilemma, 'What to do with an empty house?'(i.e. parents not at home).

\subsection{Design Objectives}

The design activity had two main design objectives:

- Gain insight into existing practice: To understand whether teenagers can create visual, verbal and kinaesthetic metaphors to describe emotions.

- $\quad$ Concept generation: Elicit emergent interaction design ideas for the display of emotions as autonomous agents.

\subsection{Method}

The design study was run at a MESS day (. Read et al., 2006) at the University of Central Lancashire and carried out by a convenience sample of 10 mixed groups of 55 young people from Years 8 and 9 (aged 12 to 14), from two Secondary Schools in the North West of England. Each group spent 25 minutes on the activity. Given time constraints and the variation in theory of mind found within this age group, teen personas, a scenario and a fantasy narrative (Iversen \& Dindler, 2008), were used to scaffold the activity. To encourage fun Play-Doh was used as a design material with an open design task that involved aspects of imaginative play. 


\subsection{Design Activity}

The ten groups of $4-7$ young people each carried out the same design activity with the same materials and structure. The group was introduced to the idea that in the future we may have technology that allows us to see each other's thoughts and feelings. They were told that the activity aimed to explore what this kind of technology might look like. Next they were introduced to a set of teen personas (Horton et al., 2012) and asked to choose one to be used by the whole group (personas convey imaginary individuals representative of a target user population). Teen personas were used to support participants to talk about emotions without worrying about divulging personal information that could leave them vulnerable. Each group was introduced to the same scenario in which their persona faced the choice between babysitting for their younger brother or having a wild party at their house. Participants were told that their teen persona was confused about the situation and was experiencing mixed emotions. Finally the narrative took a turn towards fantasy. The group was told that due to an unexplained phenomenon it was possible for other people to see the teen personas emotions floating around them. They were told that the personas emotions took on different shapes and colours and that they moved as if they had a life of their own. The group was introduced to a set of 6 plastic tokens featuring textual statements from the perspective of the persona. Each token featured an appraisal of an emotion. To describe a range of emotions, the statements were informed by the big 5 personality types identified within personality psychology (Eysenck, 1991), the prepared statements shown in table 1 were used, each mapping on to a different personality type, in order to lower the number of variables within the study.

\begin{tabular}{ll}
\hline Personality Type & Statement \\
\hline Openness to experience & 'I feel excited thinking about a party at my house.' \\
Conscientiousness & 'My Mum looks sad when I disappoint her.' \\
Extraversion & 'I feel relaxed with my mates around.' \\
Agreeableness & 'I feel tense when my mates moan about me.' \\
Neuroticism &
\end{tabular}

Table 1: Table of affective appraisal statements for the big 5 personality types 
Taking a token each, the young people were instructed to imagine what the persona's emotion might look like if it were visible and to build a Play-Doh model around the token. Each young person within the group work individually with their own box of multi-coloured Play-Doh and a time limit of 7 minutes to sculpt a model. The duration of the design activity was defined by time restrictions imposed by the MESS day format. After this time, the Play-Doh shapes were brought together and each participant was asked to describe their design and explain the rationale behind it. Data was collected by taking photos of the designs and by making audio recordings of the participants describing their designs.

\subsection{Results}

The designs were reviewed and the participants' verbal descriptions were annotated. Then the designs were coded into four categories by the first author according to the participants' verbal descriptions. Despite instructions to create shapes to represent emotions, the vast majority of designs were representational. Because of this the following categories were based on the subject matter of designs, using terms drawn from art and design theory (Botar \& Wünsche, 2011).

- $\quad$ Anthropomorphic: Designs using embodied visual metaphor.

- $\quad$ Biomorphic: Designs that personify emotions as living things.

- Abstract: Designs that externalise emotions in nonrepresentational forms.

- Object: Designs that externalise emotions as non-living things.

Of the 56 designs made by the children 25 (44.6 per cent) featured visual representations of the body, 15 (26.8 per cent) featured objects, 8 (14.3 per cent) featured living things and 8 (14.3 per cent) were abstract, (figure 1$)$. 


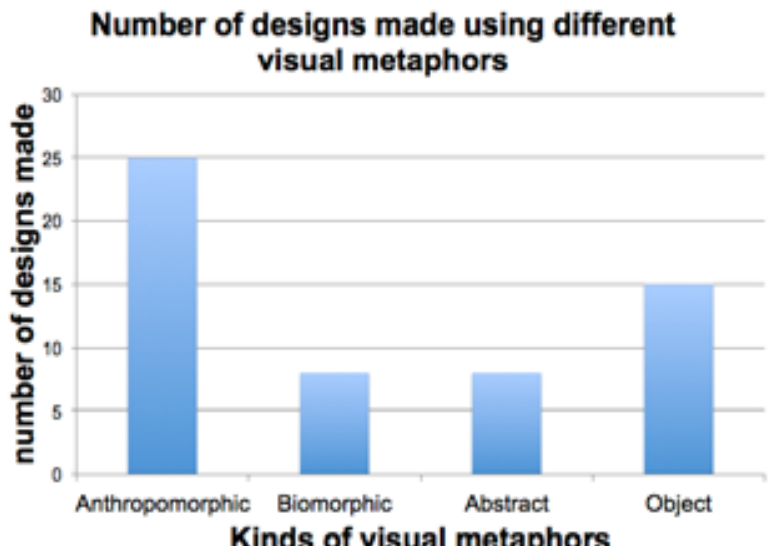

Fig 2. Number of models made using each visual metaphor style.

Participants were able to justify design decisions made for 54 of the 56 designs made.

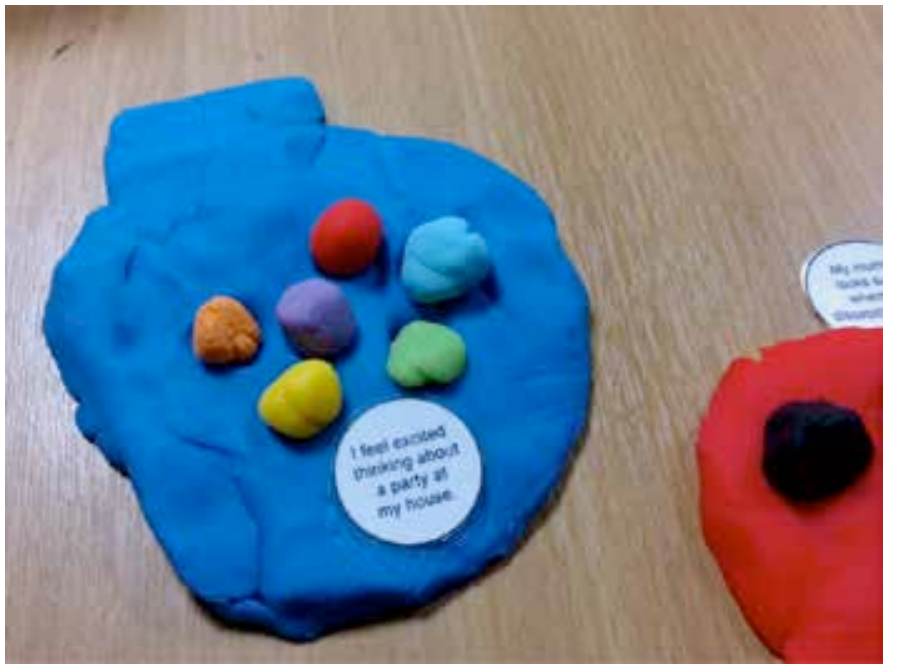

Fig 3. An Anthropomorphic design of an excited emotion.

Participant 1: 'They are all bright colours, I was going to finish it with it being a person and they're (the coloured balls) all in the stomach, all the excited feelings.' 


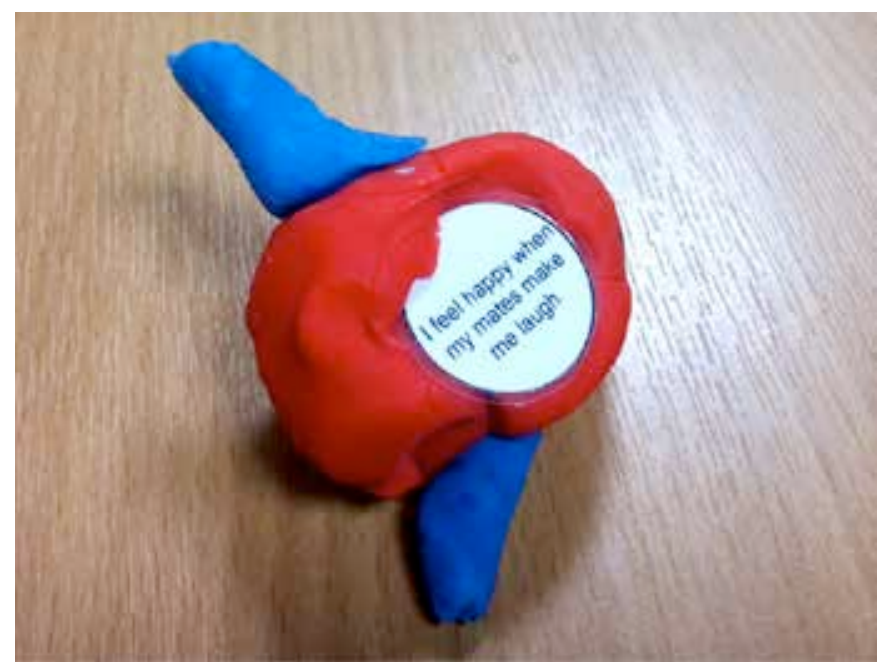

Fig 4. An Object-based design of a happy emotion.

Participant 2: 'When I think of these things I think mostly of blobby spaceships.'

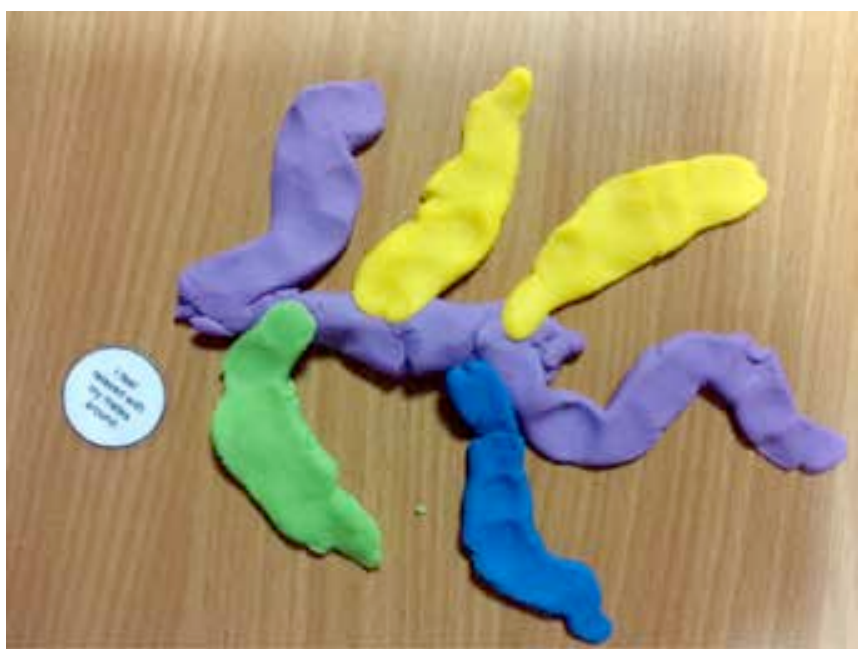

Fig 4. A Biomorphic design of a relaxed emotion

Participant 3: 'It's just different coloured wavy lines because that's how you feel when you're relaxed...it moves like a squid.' 


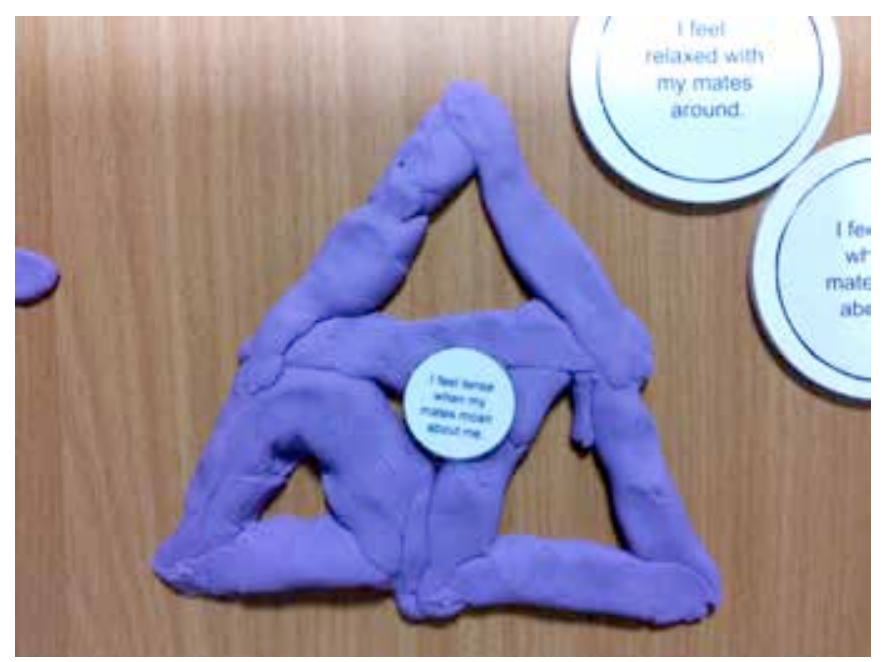

Fig 5 An Abstract design of a tense emotion.

Participant 4: 'Triangles are the strongest structure.'

Participants were asked to enact movements to describe emotions by playing with the models that they had created. They were able to verbally describe and justify movements for $67 \%$ of the designs that were created. Below is a transcript of an excerpt of a conversation between the first author and a teenage participant, discussing how the model shown in figure 6 might behave and interact with other emotions.

Researcher: "How would this one move?"

Participant 1: "Have you ever seen a squid move, it's like you have these things, tendrils, they just suck up and push forwards."

Researcher: "If this one, came across this one (a pyramid representing a tense emotion)

what would it do?"

Participant 1: "It would try and wrap itself around it, to mask the tense, underneath a

relaxed exterior."

Researcher: "What would happen to the triangle one?"

Participant 1: "It would slowly start getting smaller until it disappeared, like it's getting eaten."

Researcher: "Ok so it comes across the excited one? How might they effect each other?" Participant 1: "Well excited is a more powerful feeling than relaxed, so it would take over more, the relaxed feeling would try and stay out of its way."

\subsection{Analysis}

Analysis of the results of this study suggests that teenagers use a variety of visual metaphors to describe emotions. Although the most popular choice of visual metaphor was anthropomorphic, which accounted for $45 \%$ of the designs made, the 
other three categories were also well used, with object metaphors at $27 \%$, biomorphic accounting for $14 \%$ and abstract for $14 \%$ (figure 6). In response to research question one, $47 \%$ of the shapes designed represented the body in some way. The high use of anthropomorphic metaphors is in line with much contemporary research on emotion that places non-cognitive physiological responses, sensations and physical behaviours as being a key part of emotion (Prinz, 2012). $29 \%$ of the designs made use of objects as a visual metaphor. There was a wide variation amongst these designs, from skateboards, to rockets, to chairs. Although fewer young people used biomorphic forms, those who did were able to explain why they had chosen certain colours, shapes and visual metaphors. The anthropomorphised designs were codified further, into representations of facial features, bodily action, embodied sensation and human figures. This coding revealed that a large number of designs made use of facial expressions to convey emotion. 16 out of 28 designs related to the body making use of facial features, 2 representing embodied action such as flexing of muscles, 3 representing bodily sensation such as a bubbling stomach and 7 representing human figures. That $67 \%$ of participants were able to invent and justify movements and behaviours for their designs suggests that personification may be a useful visualisation technique for the display of mixed and complicated emotional states for teenagers. More work would be needed to understand which kinds of movements and behaviours teenagers use to describe the interaction of different emotions.

\section{Study Two}

The second study was designed to expand on the findings of the first study that teenagers use a variety of visual metaphors to describe emotions.

\subsection{Design Objectives}

The design objectives of the second study were:

- Expand on the findings of the first study: Check that teenagers can create visual metaphors to describe emotions.

- Explore the effects of materials: Discover if using 2D or 3D materials affects the visual metaphors that teenagers use to describe emotions. 


\subsection{Method}

This study took place in a classroom at a Secondary School in the North West of England. Participants were a convenience sample of 38 teenage pupils selected by a teacher. The participants were aged between 12 and 15, studying in years 7,8 and 9. Of the sample, 26 were girls and 12 were boys.

\subsection{Design Activity}

The study was a between subjects design, with two sets of independent variables, the use of 2D (coloured card) or 3D (Play-Doh) materials and the use of two different sets of emotional terms as stimuli. The dependent variables were the designs created by the participants and the terms they wrote to describe them. A list of terms for emotions, devised for the COOL project (Mazzone, 2012) were reused in this study, because they had been shown to be accessible and useful to teenagers to describe and interpret emotions. The study was split into 4 blocks, A, B, C \& D with each block offering a different combination of the two sets of dependent variables. As part of a MESS day event, the time limit for the activity was defined as 25 minutes to ensure the study aligned with scheduled classes. For each activity, the participants were split into 2 groups, either A \& B or C \& D. During each activity one group was equipped with Play-Doh and sculpting tools, the other group used coloured card and scissors. Both groups were given a design worksheet and within the groups participants worked individually. The worksheet featured 4 rectangular frames. Each frame was titled with one of the 4 emotion terms. Groups A and B used the terms, love, pride, nervous and angry. Groups C and D used the terms sad, guilty, happy and scared. Participants were asked to use the materials to create a shape to describe each of the 4 emotions and place each shape on the relevant frame. The participants were also instructed to write a textual description of what they had made in their own words, in a text box provided below their model. They were provided a space to work by themselves and given a 7 minute time limit to complete the task.

\subsection{Results}

The first author analysed the text data generated by the participants to describe their own designs and categorised the designs using the coding strategy described in Study One. From a total of 160 designs created, 65 (41\%) featured anthropomorphic visual metaphors, 15 (9\%) were categorised as biomorphic, 43 (27\%) were 
categorised as abstract and $37(23 \%)$ were categorised as object metaphors, (Table 2). 30 anthropomorphic designs were created using $2 \mathrm{D}$ materials compared to 35 using 3D (Table 3). There were 8 biomorphic designs created using 2D materials compared to 7 using 3D. 29 abstract designs were created using 2D materials compared to 14 using 3D and 27 object designs were created using $2 \mathrm{D}$ materials compared to 10 from 3D materials.

\begin{tabular}{lllll}
\hline & Anthropomorphic & Biomorphic & Abstract & Object \\
\hline Happy & 7 & 4 & 2 & 9 \\
Sad & 12 & 2 & 6 & 2 \\
Scared & 6 & 4 & 6 & 5 \\
Angry & 6 & 0 & 9 & 4 \\
Nervous & 3 & 1 & 10 & 3 \\
Guilty & 3 & 4 & 7 & 7 \\
Love & 21 & 0 & 0 & 1 \\
Pride & 7 & 0 & 3 & 6 \\
Total & $\mathbf{6 5}$ & $\mathbf{1 5}$ & $\mathbf{4 3}$ & $\mathbf{3 7}$ \\
\hline
\end{tabular}

Table 2: Categorisation of visual metaphors used by teenagers to describe emotions

\begin{tabular}{lllll}
\hline & Anthropomorphic & Biomorphic & Abstract & Object \\
\hline 2D & 30 & 8 & 29 & 27 \\
3D & 35 & 7 & 14 & 10 \\
\hline
\end{tabular}

Table 3: Categorisation of metaphors used by teenagers to describe different emotions 2D compared to $3 \mathrm{D}$ materials

\subsection{Analysis}

The percentages of designs that were categorised as either anthropomorphic or object based are largely consistent with the results of the first study (Figure 6). There was a slight reduction in the percentage of anthropomorphic designs created from $45 \%$ to $41 \%$. Similarly there was a slight reduction in object-based designs, from $27 \%$ in the first study to $23 \%$ in the second. Biomorphic design creation decreased from $24 \%$ in study 1 to $9 \%$ in the second study, with a 15 increase in abstract designs from $14 \%$ in study one to $27 \%$ in study two. 


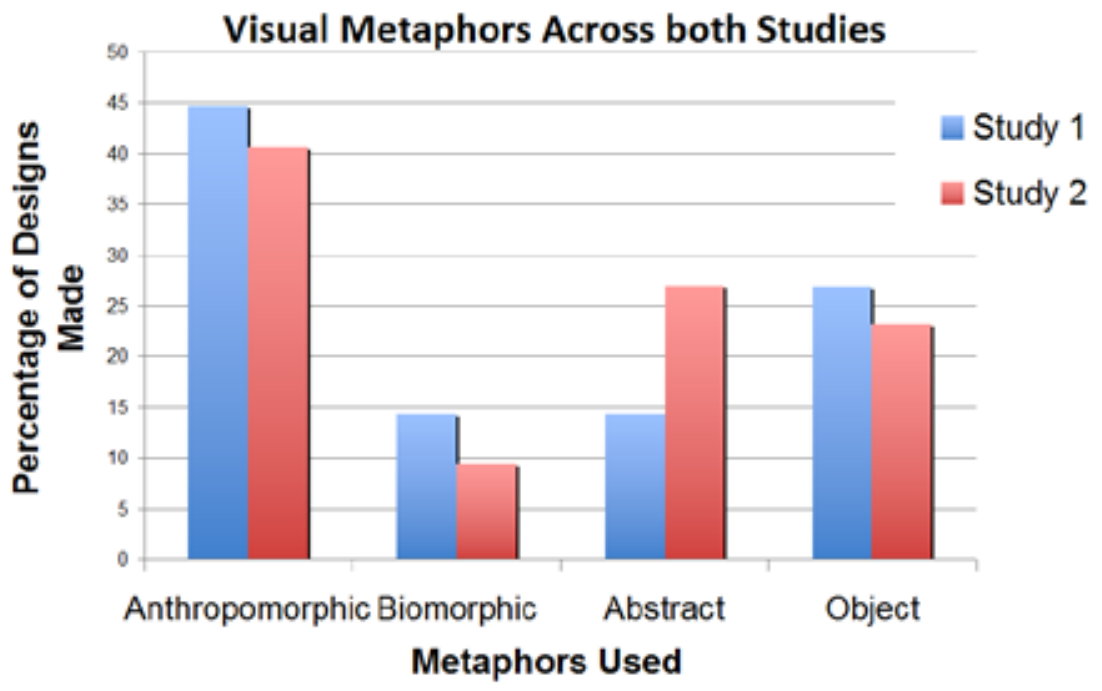

Fig. 6: Percentage of models made using different visual metaphor styles during studies 1 and 2 .

The emotional terms in this study can be categorised as positive or negative. In this basic scheme, sad, scared, angry, nervous and guilty are categorised as negative and happy, love and pride are categorised as positive. The images created to describe negative emotions featured more abstract and biomorphic visual metaphors than those created to describe emotions categorised as positive (Table 2).

An analysis of the designs produced by participants using 2D or 3D materials revealed that participants using the 3D material (Play-Doh), created more designs using anthropomorphic visual metaphors than those using coloured card, see Figure 7. 
Percentage of Designs Describing Emotions Using 2D or 3D Materials

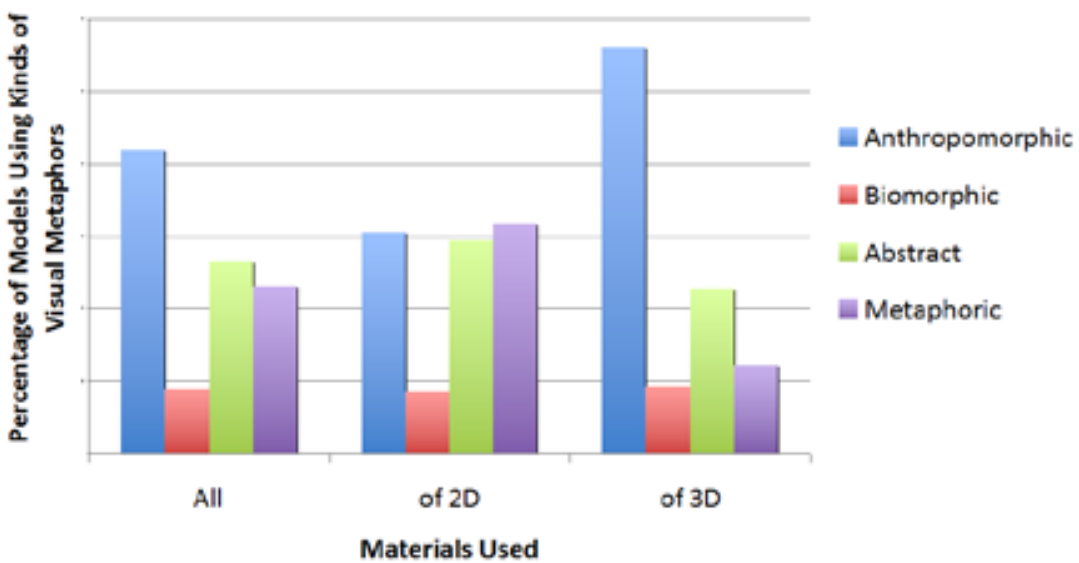

Fig. 7: Percentage of designs describing emotions using 2D or 3D materials, featuring different visual metaphor styles.

\section{Study Three}

Informed by the findings of this research, a prototype app was designed to display mixed and complex teenage emotions. The app transferred ideas explored in this study into the digital realm and allowed for the integration of knowledge gained here, with new explorations of the use of interactive movement behaviours to describe the interaction of different emotions. The app allowed users to select and interact with externalised and personified emotions, visualised as autonomous agents. Users control which emotions are brought to life onscreen, selecting different visual designs and controlling movement behaviours with a set of sliders. 


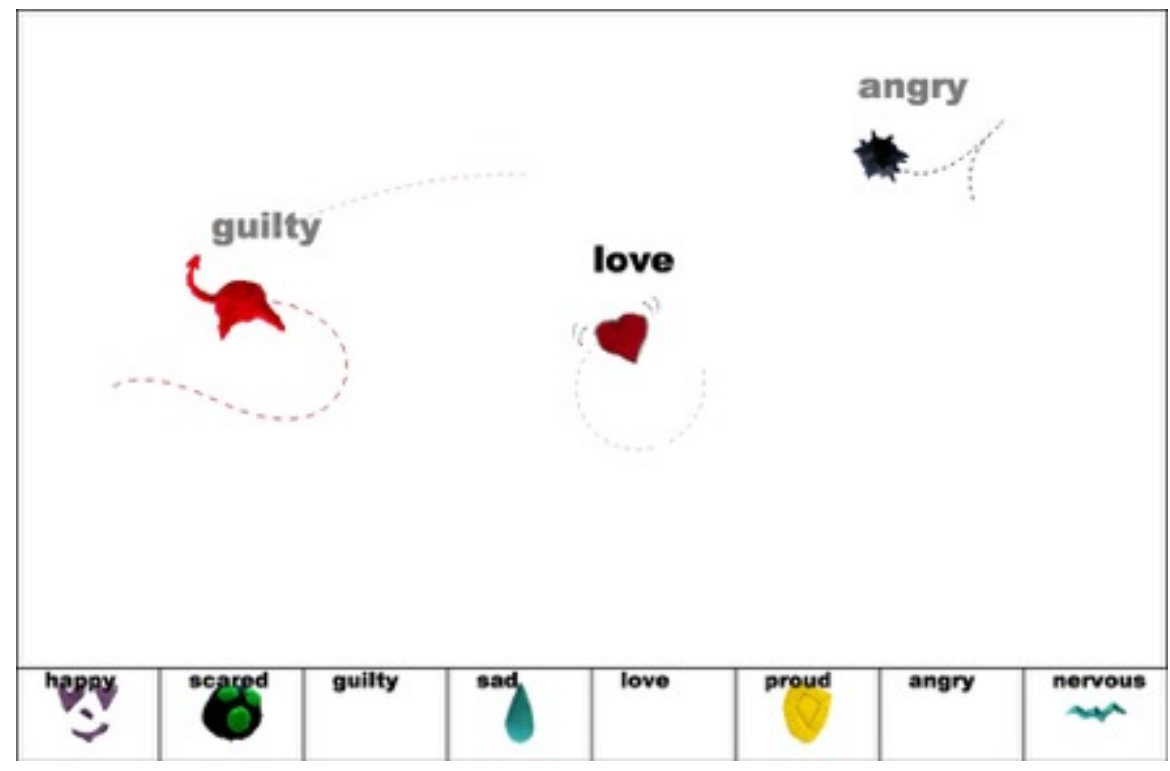

Fig.8 Screenshot of the prototype mobile app Empath.

A third study was conducted to investigate the use of early evaluations of prototypes to stimulate discussion on possible use contexts for mobile affective displays and any ethical issues that the prototype raised. The second evaluation study was run at FACT, the Foundation for Art and Creative Technology in Liverpool as part of a creative summer school. This evaluation activity was carried out by 1 mixed gender and mixed age group from a convenient sample of 7 young people from Liverpool, aged 11 to 18 . The participants were recruited through their involvement with the summer school.

\subsection{Design Objectives}

The study was a formative, exploratory evaluation conducted in order to gain an understanding of teenage attitudes and perceptions towards affective displays and their social use.

\subsection{Design Activity}

The participants were given information about the development of the project and its aims. To avoid the risk of satisficing (giving superficial responses that are 
perceived to be acceptable) the young people were told that the app (Figure 8) had been designed by another member of the research team (i.e. not the researcher conducting the study). Participants were introduced to a set of two teen personas, adapted from those in (Horton et al., 2012) for the purposes of this study, and asked to select one each. The set of personas included one male and one female teenager. The personas both featured the same scenario, in which the persona was lead protagonist. In this scenario, the persona had taken advantage of their parents being away and opened their house to a wild party. The party had started well, but now it was full of strangers and their persona is experiencing mixed feelings about the whole situation. Participants were given an Android tablet each, and were instructed to use the app. They were told that their task was to use the app to control the movement and appearance of emotions to describe how their teen persona would be feeling at this point in the scenario. Participants were allowed 5 minutes to use the application individually before participating in a focus group discussion to evaluate the application, in which participants were asked to imagine how the teen persona would feel about the app.

\subsection{Results}

The discussion transcript was analysed by the first author and participants' comments about the app were coded into three categories, personal development, relationships and privacy. These categories were selected in response to the issues that participants raised during the discussion and the value judgements that were perceived to underpin their comments. Each monologue contributed by a participant was treated as a separate comment and pseudonyms are used instead of real names in the following discussion. Of the 20 comments in the transcript, 6 focused on how the use of mobile emotion displays could affect teenagers relationships with others, echoing Fitton et als (2013) inclusion of the 'desire for association with peers' as a key characteristic of teenagers.

Ethan: "If people would be able to view your emotions, you would be more self-conscious about how you were feeling, if people could see that you were angry then people could stay away from you."

The need for teenagers to develop the ability to describe and reason about their emotions, emphasized by Fonagy et al (2002) was also valued by participants who made seven comments discussing how mobile affective displays could support personal development. Seven of the twenty comments made by the group concerned how affective systems like these might affect teenager's right to privacy.

Danny: "That's why I would prefer to keep my emotions in me, just to be sure, because anything can get hacked now." 
The comments were also coded by sentiment and categorised as either benefits, neutral or concerns in order to gain some more general evaluative insights within the three categories

\begin{tabular}{lccc}
\hline & Relationships & Privacy & Personal Development \\
\hline Benefits & 1 & 0 & 5 \\
Neural & 0 & 2 & 2 \\
Concerns & 5 & 5 & 0 \\
\hline
\end{tabular}

Table 4: Number of comments raised by teenagers in focus group discussion.

Of the six comments about how the app could affect relationships, one described a benefit and five described concerns. Of the seven comments relating to privacy, five raised concerns and two were neutral, whereas of the seven comments on how the app could affect personal development five described benefits and two were neutral. A transcript of the focus group discussion is included in the appendix at the end of the book.

\subsection{Analysis}

When asked to consider how a teen persona might feel about the mobile app, teenagers taking part in the evaluation raised twice as many issues relating to relationships and privacy as they did to personal development. The issues raised about privacy and how use could affect relationships were overwhelmingly negative, whereas comments about the apps potential effect on personal development were largely positive. This suggests that for these teenagers the value of affective displays is judged not only in terms of personal development, but that the teenagers are also considering the wider contexts of use and associated implications (such as the possible consequences of inadequate privacy). 


\section{Discussion}

Much of the CCI research exploring the design of emotion displays has worked within the emotion as information paradigm. Both the COOL (Mazzone 2012) project and the SenseMS (Amin et al., 2005) project, found that teenagers preferred to use designs featuring facial expressions when asked to describe emotions accurately. Both these projects designed systems that aimed to communicate emotional information as unambiguously as possible using one display method to describe a range of emotions. The present study also found that teenagers use anthropomorphic visual metaphors the most to describe emotions. This emphasis on non-cognitive (Hoffman, 1986) and embodied (Prinz, 2012) interpretations of emotion fits well with contemporary theories of emotion.

The studies described in this chapter also discovered that teenagers have a more complex approach to the design of emotion displays than has been previously thought. A fine-grained approach was taken to understand the different ways that teenagers use visual metaphor's to describe different emotions. Although teenagers taking part in this study created anthropomorphised designs the most, they used a range of visual metaphor styles to describe emotions. This suggests that while anthropomorphised visual metaphors remain central to teenager's representation of emotion, a variety of visual metaphor styles should be considered when designing affective systems for and with this group. This would both echo existing practice amongst teenagers as captured in this study and encourage the collaborative interpretation of the meaning of emotions amongst peers as encouraged by Boehner et al. (2007). Interaction designers developing affective systems to support the teenage development of mentalised affectivity (Fonagy et al., 2002), should offer the affordance of 'many paths, many styles' (Resnick \& Silverman, 2005) for the display of emotions. As Fonagy et al (2002) have stated, the ability to describe and find meaning in emotions is of vital importance to teenage development and mental health. Teenagers participating in this study made more use of abstract and biomorphic designs to describe 'negative' emotions such as scared, angry, nervous and guilty. That teenagers use different visual metaphors to describe negative emotions is a new finding and has implications for interaction design with children. Abstraction and biomorphism are already used as techniques within art and narrative therapy to externalise and personify negative emotions. It seems likely that their ambiguity and their lack of relation to the body make these kinds of designs useful to teenagers to separate themselves from problematic emotions and think critically about them. That teenagers have used these visual metaphors and techniques whilst designing an interactive system, suggests that they are transferrable from therapy settings to the design of affective displays. 
Participants of this study created more designs describing emotions featuring anthropomorphic visual metaphors when they were using Play-Doh. This suggests that choice of materials has an effect on teenage design contributions for affective displays. The results of this study do not identify whether the key factor here is the difference between 2D and 3D materials or hard and soft materials.

\subsection{Reflections}

Findings from this work support the view that it is particularly important teenagers participate in the design these kinds of systems where adults simply do not have the insights and understandings teenagers themselves can provide. The activities were designed to be accessible and meaningful to teenagers, using techniques that have been shown to work with this age group and ethical guidelines set out by the ChiCI group.

By asking teenagers to actively design their own emotion displays, instead of categorising simplified diagrams of facial expressions as with the COOL project, the design activities allowed participants more freedom to explore different kinds of visual metaphors. Although participants still used anthropomorphised visual metaphors the most the use of $2 \mathrm{D}$ and $3 \mathrm{D}$ materials has revealed a more nuanced picture of how teens prefer to visualise emotion and suggested new ways to describe difficult emotions. This decision to reject established visualisation methods as a default starting point could be applied to different visualisation and design activities involving teenagers in the context of mobile apps, web sites etc.

The context of app design, a design space that many teenagers are interested in, acted as an effective motivator for engagement in creative activities that have already been shown to be of benefit to teenage development. By creating visual metaphors to describe different kinds of emotions, participants constructed their own visual language to describe and make sense of their own and other people's emotions. As one participant said when evaluating the mobile app.

Josh: "It might help people explain their emotions, if they have difficulty communicating them, they could show them in a visual way."

Activities in the first and the third study, exploring the use of personification and externalisation to describe the behaviour of emotions as digital autonomous agents, offered teenagers a new way of describing mixed emotions. In the first study, teenagers were able to easily invent interactive behaviours for emotions, of the kinds often seen in dynamic game mechanics. For example one participant described movements they were enacting with models of emotions. "It would slowly start 
getting smaller until it disappeared, like it's getting eaten." As many teenagers are used to encountering the interaction of agents in dynamic decentralised systems whilst playing computer games, it is likely that this design activity builds on their existing implicit knowledge of these systems. This application of using a 'decentralised systems' way of thinking in art-therapy techniques such as externalization and personification is valuable because it enables teenagers to describe complicated and mixed emotions in a language that makes sense to them.

The first two studies in this research we conducted as part of MESS days. This format enables researchers to access to a large number of teenagers in a short space of time and is an effective way to involve difficult to reach teenagers, who might not otherwise access participatory design activities through engagement with arts or other community provisions. MESS days are experienced by participants as part of school activities, the behavioural expectations and social norms in school are likely to affect design contributions, particularly when designs are describing the private subject of teenage emotions. It is possible that participants in this study selfcensored design contributions that they may otherwise have shared in another setting. The effect of social context on the teenage design of affective systems could be researched carrying out the same activities across formal educational and informal social settings. The use of MESS days also placed constraints of the time allowed for study activities and demands on the researchers to ensure everything was reset and prepared quickly as group of participants moved between activities, these practical organisational issues need to be considered carefully for other researchers wishing to use a similar approach with success.

The description of emotions is a highly subjective task for all ages. This is particularly the case for teenagers both due to the social pressures of adolescence and the different rates that teenagers develop theory of mind and social skills. For these studies it was important that the design stimulus was both accessible, engaging and consistent across the study group. In response to Fitton and Bell's (2014) research question of "What are the appropriate methodologies for engaging teenagers in HCI research?", we found that combining teen personas with a fantasy narrative, was an effective way to frame a lo-fi design activity aiming to stimulate innovative design thinking whilst dealing with a potentially sensitive topic for teenagers, emotion. Participants were able to quickly understand the design space, the visual display of emotion and intended use context. The pseudonymity that personas offer are particularly useful to support teenagers to share visual and verbal descriptions of emotions. The methods used in this study also addressed the question of "How can we gain insights into unknown teen populations?" by demonstrating that teenage design contributions can reveal new insights, in this case into teenage preferences for the display of emotion. It is likely that this combination of teen personas and fantasy narrative as stimulus for lo-fi design activities will prove useful to those looking to engage emergent teenage brains with innovative design thinking across a range of spaces and technologies. It is also likely that with 
fine grained analysis, these design contributions will reveal new and fascinating things about teenage experiences of technology.

The use of role play with models created by the participants was an effective and intuitive way for teenagers to demonstrate the personification of emotions. This is demonstrated by the ease with which $66 \%$ of participants were able to invent distinct movements to represent the interactions of different emotions. Although this helped the researcher gain an understanding of which kinds of movements these teenagers might find useful to describe emotions as autonomous agents, this was not captured quantitatively. In future studies this data could be captured by filming or otherwise tracking the movement of models as participants played with them.

An important limitation of this research is the difference in design between studies one and two. Study one made use of teen personas and narrative framing for design stimulus, whereas study two used basic text descriptions of emotions. All of the participants in study one worked with Play-Doh, but half of the participants in study two created drawings. Participants in study one were asked to elaborate verbally on their results, whilst in study two they were asked to write text descriptions, which due to the natural variance in literacy skills, could differ greatly between the age groups. Because of these inconsistencies, it is not possible to claim that the second study validates the first one. Researchers conducting similar studies should attempt to replicate the same design activity, in order to validate findings or make one of the changes described here, to understand its effect.

The design of affective displays for teenagers is a new area of research within HCI. The design of affective systems for adults is already a complex challenge, combining this with the developmental needs of adolescents, the lack of understanding we have of teen computer interaction can make this feel like a leap into the unknown. As this generation of teenagers face the developmental challenges in a digital culture in which tastes, boundaries of privacy and behavioural norms are constantly moving, there is a greater risk that technologies designed to support teenage development, could not only fail to satisfy this aim, but actually cause harm. The focus group discussion was a useful way for researchers to gain an understanding of teenage perceptions and attitudes towards mobile emotion displays. The informality of the setting and the activity supported a relaxed discussion in which participants appeared to speak their minds, although the presence of peers is likely to have shaped their behaviour and the points they raised. The discussion suggested that these teenagers would rate the value of an affective display not just for the impact it has on their personal development, but also their relationships and right to privacy. Although this study has found that theory and techniques from therapeutic settings, such as the externalisation and personification of emotions can be transferred to the design of affective systems, it is important to understand key differences between the therapeutic context, with its emphasis on one to one private relationships and the complex networked social life of teenagers. 
Because of this, it is vital that teenagers are involved in the design of affective systems, both to ensure that emotion display methods are meaningful to teenagers and that they don't make vulnerable teenagers more vulnerable. Ultimately, if technology is going to pervade the emotional life of teenagers, then it is ethically important that teenagers have a voice in how that technology is designed.

\section{Conclusions and Further Work}

This chapter explored the design of affective applications with teenagers and posed 2 key research questions of which kinds of visual metaphors do teenagers use to describe emotions? (RQ1) and how does the use of different materials affect teenage designs of affective displays? (RQ2). In response to research RQ1, this study has three key conclusions:

- $\mathrm{C} 1$. Teenagers use anthropomorphic visual metaphors the most to describe emotions.

- $\quad \mathrm{C} 2$. Teenagers use a variety of visual metaphors to describe emotions.

- C3. Teenagers make more use of abstract and biomorphic designs to describe 'negative' emotions such as scared, angry, nervous and guilty. In response to RQ2 this work found:

- C4. Teenagers are more likely to create designs describing emotions featuring anthropomorphic visual metaphors if they are using soft malleable and three dimensional materials.

While this chapter contributes a range of valuable insights and understandings around the visual metaphors that teenagers use to describe different emotions, there is still much to explore within this space. For example, more work needs to be done to explore whether the model developed by Read et al (2013), can be applied to understand exactly how the affordances of materials effect teenagers designs of affective displays.

Further work is planned to develop and evaluate interactive systems featuring teenage emotions visualized as autonomous agents, capable of interacting with their environment and one another. This work will aim to combine the benefits of externalisation and personification with the kinds of technological features that are known to appeal to teenagers such as interaction, gameplay and networked collaboration. It will be informed by the modelling and simulation approaches used by modelling toolkits (Resnick 1997) and serious games (Susi et al. 2007).

The importance of technologies ability to support vital peer relationships has been identified by Read (2013) and Fitton (2014), but its importance to the design of affective systems to this group is new. Read (2011) has offered useful methods to capture teenage perceptions of safety and privacy in cloud computing. The issue 
of how the design of affective systems responds to teenagers need to develop the ability to describe, reason about and share emotions and their need for tighter social relationships with peers whilst maintaining their right to privacy is new to HCI. This research challenge will require affective systems to be designed and evaluated from a perspective of social use and privacy as well as just individual personal development. The overall contribution of this work to the field of Teen-CI is a categorisation of the visual metaphors teenagers use to describe different emotions along with the associated methods that were successfully used to engage teenagers exploring and representing emotions. It is hoped that these findings be useful to interaction designers and researchers developing affective systems for and with teenagers.

\section{References}

Amin, A. K., Kersten, B. T. A., Kulyk, O. A., Pelgrim, P. H., Wang, C. M., \& Markopoulos, P. (2005). SenseMS : A User-centered Approach to Enrich the Messaging Experience for Teens by Non-verbal Means, 161-166.

Astington, J. W., Harris, P. L., \& Olson, D. R. (1990). Developing theories of mind. Cambridge University Press.

Bang, A., Krogh, P., Ludvigsen, M., \& Markussen, T. (1993). The Role of Hypothesis in Constructive Design Research. Designresearch.aalto.fi, 1-11.

Bishop, C. (2005). The Social Turn: Collaboration and Its Discontents. Artforum. Retrieved from

Boehner, K., DePaula, R., Dourish, P., \& Sengers, P. (2007). How emotion is made and measured. International Journal of Human-Computer Studies, 65(4), 275-291. doi:10.1016/j.ijhcs.2006.11.016

Botar, O. A. I., \& Wünsche, I. (2011). Biocentrism and modernism. Ashgate Publishing, Ltd.

Butler, S., Guterman, J. T., \& Rudes, J. (2009). Using puppets with children in narrative therapy to externalize the problem. Journal of Mental Health Counseling, 31(3), 225-233.

Carey, M., \& Russell, S. (2002). Externalising - commonly asked questions. International Journal of Narrative ..., 1-11. 
Chandler, M., Astington, J. W., Harris, P. L., \& Olson, D. R. (1988). Doubt and developing theories of mind. Developing Theories of Mind, 1,387-414.

Clynes, M., \& Menuhin, Y. (1977). Sentics: The touch of emotions. Anchor Press Garden City, NY.

Druin, A. (1999). Developing Cooperative New Technologies Inquiry : for Children with Children, 592-599.

Eysenck, H. (1991). Dimensions of Personality: 16, 5 or 3? - Criteria for a taxonomic paradigm. Personality and Individual Differences, (1985).

Fitton, D., \& Bell, B. (2014). Working with Teenagers within HCI Research: Understanding Teen-Computer Interaction. Proceedings of the British Computer Society Conference on Human-Computer Interaction, 201-206. doi:10.14236/ewic/hci2014.23

Fitton, D., Read, J. C. C., \& Horton, M. (2013). The challenge of working with teens as participants in interaction design. In CHI '13 Extended Abstracts on Human Factors in Computing Systems (pp. 205-210). New York, NY, USA: ACM. doi:10.1145/2468356.2468394

Fitton, D., Read, J., \& Horton, M. (2013). The Challenge of Working with Teens as Participants in Interaction Design. CHI'13 Extended Abstracts on Human ..., 205-210.

Fonagy, P., Gergely, G., \& Jurist, E. L. (2002). Affect regulation, mentalization and the development of the self. Karnac Books.

Froggett, L. (2011). New Model Visual Arts Organisations \& Social Engagement, (October).

Guha, M., Druin, A., \& Chipman, G. (2005). Working with young children as technology design partners. Communications of the ..., 48(1), 39-42.

Guha, M. L., Druin, A., Chipman, G., Fails, J. A., Simms, S., \& Farber, A. (2004). Mixing ideas: A New Technique for Working with Young Children as Design Partners. Proceeding of the 2004 Conference on Interaction Design and Children Building a Community - IDC '04, 35-42. doi:10.1145/1017833.1017838

Hoffman, M. L. (1986). Affect, cognition, and motivation. Handbook of Motivation and Cognition: Foundations of Social Behavior, 1, 244-280. 
Horton, M., Read, J., Fitton, D., Little, L., \& Toth, N. (2012). Too Cool at SchoolUnderstanding Cool Teenagers. PsychNology Journal, 10(2), 73-91.

Iversen, O., \& Dindler, C. (2008). Pursuing aesthetic inquiry in participatory design. ... Anniversary Conference on Participatory Design

Klein, M. (1929). Personification in the play of children. The International Journal of Psychoanalysis, 1-7.

Lutz, C. (1988). Unnatural emotions: Everyday sentiments on a Micronesian atoll and their challenge to Western theory. University of Chicago Press.

Marti, P., \& Rizzo, A. (2003). Levels of design: from usability to experience. $H C I$ International 2003, 10th International ..., (July).

Mazzone, E. (2012). Designing with Children : Reflections on Effective Involvement of Children in the Interaction Design Process, (June).

Mazzone, E., Read, J., \& Beale, R. (2008). Understanding children's contributions during informant design. Proceedings of the 22nd British HCI ..., 2-5.

Papert, S., \& Harel, I. (1991). Situating constructionism. Constructionism.

Picard, R. W. (1995). Affective Computing, (321).

Picard, R. W., Papert, S., Bender, W., Blumberg, B., Breazeal, C., Cavallo, D., ... Strohecker, C. (2004). Affective Learning - A Manifesto. BT Technology Journal, 22(4), 253-269. doi:10.1023/B:BTTJ.0000047603.37042.33

Prinz, J. (2012). Emotion. (P. Calvo \& T. Gomila, Eds.)The Cambridge Handbook of Cognitive Science. Cambridge University Press (In Press).

Read, J., \& Bekker, M. (2011). The nature of child computer interaction. Proceedings of British HCI 2011, (1994), 1-9.

Read, J. C., \& Beale, R. (2011). What Teenagers think about when they think about Safety in the Cloud.

Read, J. C. C., Horton, M., Iversen, O., Fitton, D., \& Little, L. (2013). Methods of working with teenagers in interaction design. In $\mathrm{CHI}$ ' 13 Extended Abstracts on Human Factors in Computing Systems (pp. 3243-3246). New York, NY, USA: ACM. doi:10.1145/2468356.2479657

Read, J. C., Fitton, D., \& Horton, M. (2013). Theatre, PlayDoh and Comic Strips: Designing Organic User Interfaces with Young Adolescent and Teenage 
Participants. Interacting with Computers, 25(2), 183-198. doi:10.1093/iwc/iws016

Read, J. C., \& Markopoulos, P. (2013). Child-computer interaction. International Journal of Child-Computer Interaction, 1(1), 2-6. doi:10.1016/j.ijcci.2012.09.001

Read, J., MacFarlane, S., \& Kelly, S. (2006). The ChiCI group. CHI'06 Extended ..., 6-9. Retrieved from http://dl.acm.org/citation.cfm?id=1125517

Resnick, M. (1997). Turtles, Termites, and Traffic Jams: Explorations in Massively Parallel Microworlds. Book. MIT Press.

Resnick, M., \& Silverman, B. (2005). Some reflections on designing construction kits for kids. Proceeding of the 2005 Conference on Interaction Design and Children IDC 05, 117-122. doi:10.1145/1109540.1109556

Reynolds, C. W. (1999). Steering behaviors for autonomous characters. In Game Developers Conference (Vol. 1999, pp. 763-782).

Salovey, P., \& Mayer, J. (1989). Emotional Inteligence. Imagination, Cognition and Personality.

Velásquez, J. (1997). Modeling emotions and other motivations in synthetic agents. Proceedings of the National Conference on Artificial ....

White, M. (2006). Narrative practice with families with children: Externalising conversations revisited. White, $M \&$ Morgan, A.: Narrative Therapy with Children and Their Families.

Xu, D., Read, J., Sim, G., \& McManus, B. (2009). Experience it, draw it, rate it: capture children's experiences with their drawings. ... on Interaction Design and Children, 3-7. 


\section{Appendix}

Transcript of interview in Study 3, from chapter 'Designing Teenage Emotions with a Life of their Own'.

Researcher: "How do you think teenagers like Ian or Amanda would feel about using something like this?"

Ella: "I think it would be quite helpful to them, because teenagers are meant to be in a time of struggle and you're just realizing who you are and who you want to be, so therefore, using something like that to gather your emotions might be helpful, instead of having to talk to someone about it, you could just collect them all in there."

Michael: "But some people don't like interactive things like that do they, some people are just quiet and don't show their emotions until later on, or some people just show their emotions at the moment."

Danny: "Some people eight not want to put their emotions into something that other people might see."

Researcher: "How do you think that teenagers like Ian or Amanda would feel about sharing something that they did using something like this, with other people? How would that work? What would be the positives and negatives with it?"

Danny: "You could stick in a thing to help them, so if they stick a certain thing in, then it might say 'try to do something to calm yourself down.' or 'try to do something to make yourself happy.' It could say, 'Try take a bath to make yourself happy.',

Amanda: "It might help people explain their emotions, if they have difficulty communicating them, they could show them in a visual way."

Researcher: "What are the risk with people putting their emotions out there?" Ella: "If someone knows you and they go on to your tablet and find out that you were angry or whatever, then they then know what you felt angry over and what you did that day, therefore they could start making you feel angry again."

Ethan: "I had another positive, for people with Asperger's who might find it hard to find emotions, this could be really helpful, and it could be an easy way."

Researcher: "Why?"

Ethan: "Because it's more visual."

Danny: "It might not help that much though, because it's still just sliding thing up or down.'

Researcher: "If we were to imagine the 100 years from now and think about the technologies that we might be having then, if the sky is the limit and we are thinking these slider things don't give you that much control, and they aren't that much fun, then what could we have instead?"

Jacob: "In a hundred years, they could actually, allow human minds to get access to the internet, via virtual replicas of ourselves we could make games

of our own."

Researcher: "Would anyone fancy that?"

Amanda: "Yes."

Ethan: "Yes."

Michael: "I don't know what he said, but yes."

Researcher: "So is this what you are saying, that there could be virtual versions of yourselves, so your thoughts could be on the internet."

Jacob: "Well technically you would be on the in the internet, not on, but in." 
Researcher: "If your emotions are in the internet, then what are the positives and negatives of that in your everyday life?"

Amanda: "They are very public, but that might be a good thing if people were more frank with each other, it would change society though. You would have to try it out on a community of people and see how it would change their behaviour."

Researcher: "Any more thoughts on if the sky was the limit how those ideas might work?"

Ethan: "If people would be able to view your emotions, you would be more selfconscious about how you were feeling, if people could see that you were angry then people could stay away from you."

Ella: "You might actually be able to program something to read your emotions, just be reading your thoughts and your face, similar to what he was saying, so it might be better because you wouldn't have to put in your emotions, it would just automatically know."

Researcher: "So you wouldn't have to go through a screen?"

Researcher: "So we were talking about the risk as to people being able to see if you were angry."

Danny: "People might rather than actually so their true emotions, they might want to mask their true emotions and do something different, so not actually show what their emotions are, when other people are looking at it."

Ella: "There should be a privacy setting, so that people can only see half of the emotions that you want them to see, so that you are able to explore all of your emotions in to make you feel better, but then people can't see all of them. But the problem with that is the people who need to know, like all of your emotions like your parents or whatever, won't know because of the private settings, so they wouldn't be able to find out. Therefore you could just put 'Happy' and 'Cheerful' when actually you are just depressed."

Researcher: "So possibly we are just reproducing the same problems that we have in the real world. Any thoughts on how you could get around that?"

Danny: "You could have it like on Facebook, so that when you post something only certain people see it, only the people that need to know."

Researcher: "Thinking of the people you know, the organizations in your life, businesses, and governments, people that you know in your social life, who would and who wouldn't you trust?"

Danny: "I wouldn't trust nearly anyone really. If you think of everything now, it's all gone public, Facebook and twitter, everyone can see it, so I think your emotions now are the only thing that you've got that are private. So if you make that public, then you've not got anything to hold onto."

Ethan: "If you were in street just walking about, you wouldn't want everyone to know your emotions. Maybe if you could say why you were angry, then people could avoid that, and not just say 'I'm Angry.",

Nadine: "You could have more emotions, hungry, jealousy stuff like that."

Ella: "If someone is out to get you angry, then they would automatically know what they need to do to make you upset and you would just get it every single day, I mean people would know how to make you happy as well so that make help, but if people know how to make so upset, then you are going to end up being so bullied and so miserable that your school life or your work life or whatever, I think it could also increase the amount of suicides because people, are just being upset constantly, so they might just end up killing themselves."

Ethan: "There should be a way to block them."

Researcher: "There are loads of risks."

Ethan: "There are risks with everything though, it's like social network, YouTube, there' always a risk, so it wouldn't just be with that, it would be everything."

Danny: "That's why I would prefer to keep my emotions in me, just to be sure, because anything can get hacked now." 
